\title{
An Innovative Mathematical Model: A Key to the Riddle of $\mathbf{H b A}_{1 \mathrm{c}}$
}

\author{
Mahdi Kahrom \\ Division of Endocrinology and Metabolism, Bu-Ali Research Institute, Mashhad University of Medical Sciences,
} Mashhad 9195977178, Iran

Correspondence should be addressed to Mahdi Kahrom, kahrom@irimc.org

Received 8 February 2010; Accepted 13 June 2010

Academic Editor: Robert R. Henry

Copyright (c) 2010 Mahdi Kahrom. This is an open access article distributed under the Creative Commons Attribution License, which permits unrestricted use, distribution, and reproduction in any medium, provided the original work is properly cited.

$\mathrm{HbA}_{1 \mathrm{c}}$ is a standard clinical assessment of glycemia and the basis of most data relating glycemic control to complications. While daily blood glucose testing gives a picture of day-to-day fluctuations, the $\mathrm{HbA}_{1 \mathrm{c}}$ test offers an overview of how well glucose has been controlled over the past 4 months. I devised an innovative mathematical model to describe novel equations governing $\mathrm{HbA}_{1 c}$ which enables analysis of $\mathrm{HbA}_{1 \mathrm{c}}$ behavior and provides emerging new concepts in assessment of diabetes management. Linear relationship of $\mathrm{HbA}_{1 \mathrm{c}}$ and mean plasma glucose along with the kinetic analysis of $\mathrm{HbA}_{\mathrm{lc}}$ formation has been used as the basic suppositions to construct this model. The main application of this devised model is prediction of mean plasma glucose at any desired point in time after a change in therapy and with great certainty. This model also appraises the pattern of $\mathrm{HbA}_{1 \mathrm{c}}$ changes over time and provides a unique opportunity to address common mistakes and misconceptions in routine application of $\mathrm{Hb}_{1 \mathrm{c}}$ that could have potentially important implications on diabetes control.

\section{Introduction}

Maintenance of blood glucose levels as close as possible to the nondiabetic range over time is an important goal in the current management of patients with diabetes. Assessment of a patient's diabetes management can be accomplished by directly analyzing the pattern of multiple blood glucose samples drawn over time [1]. However, a high degree of cooperation is required on the part of the patient to collect a sufficient number of blood glucose samples that adequately represent typical diurnal glucose patterns. Once collected, statistical analysis is then necessary to assess the central tendency and variability of glucose levels. As an alternative, a patient's $\mathrm{HbA}_{1 \mathrm{c}}$ level can be easily and conveniently determined from a single blood sample.

A large number of studies have shown that $\mathrm{HbA}_{1 \mathrm{c}}$ is strongly associated with the preceding mean plasma glucose (MPG) over previous weeks and months [2-5]. Based on the statistical relation of $\mathrm{HbA}_{1 c}$ and MPG, $\mathrm{HbA}_{1 c}$ is widely used as a clinical estimation of MPG, and it has been proposed as a diagnostic criterion for diabetes, as well [6]. $\mathrm{HbA}_{1 \mathrm{c}}$ has, therefore, become a standard assessment of glycemia [7] and a standard part of diabetes management.
One of the most important limitations of $\mathrm{HbA}_{1 \mathrm{c}}$ is that it is not applicable in short intervals. Erythrocyte life span in normal conditions averages $\sim 120$ days, and the glycation of hemoglobin $(\mathrm{Hb})$ is a continuous, nonenzymatic, relatively slow and nearly irreversible process [8] that means change in effects of previous glycation on $\mathrm{Hb}$ takes several weeks to months to occur. To permit a much clearer assessing of diabetes management, it is generally recommended that the $\mathrm{HbA}_{1 \mathrm{c}}$ assay be used every 2-3 months. Ideally, if measured each 120 days (4 months) it gives a precise estimation of MPG over preceding 4 months, reliably comparable to previous $\mathrm{HbA}_{1 c}$ value. If measurement is taken earlier than erythrocyte life span intervals (4 months), because of existing previously glycated $\mathrm{Hbs}$ which have not reached end of their lives, the estimated MPG would be affected by previous plasma glucose levels. This would be an important issue, and if measured following a significant variations in plasma glucose during changes in patient's diabetes control or medication, then it would end to a remarkable error in estimation of MPG.

I devised an innovative mathematical model to describe novel equations governing $\mathrm{HbA}_{1 \mathrm{c}}$ which enables analysis of 
$\mathrm{HbA}_{1 \mathrm{c}}$ behavior and provides emerging new concepts in assessment of diabetes management.

\section{Suppositions and Theory}

Quarterly $\mathrm{HbA}_{1 \mathrm{c}}$ and corresponding seven-point capillary blood glucose profiles obtained in the DCCT have been analyzed to define the relationship between $\mathrm{HbA}_{1 \mathrm{c}}$ and MPG. $\mathrm{HbA}_{1 \mathrm{c}}$ is linearly related to MPG based on linear regression analysis weighted by the number of observations per subject (Figure 1), producing a relationship of [9]

$$
\operatorname{MPG}(\mathrm{mg} / \mathrm{dl})=35.6 \times \mathrm{HbA}_{\mathrm{lc}}-77.3 .
$$

or

$$
\mathrm{HbA}_{1 \mathrm{c}}=\frac{1}{35.6} \mathrm{MPG}+2.17
$$

MPG at increasing levels of $\mathrm{HbA}_{1 \mathrm{c}}$ is shown in Table 1 based on DCCT data correlating $\mathrm{HbA}_{1 c}$ with MPG using 7point blood glucose profiles along with ADAG data using continuous glucose monitoring systems $[5,9]$.

The kinetic analysis of $\mathrm{HbA}_{1 c}$ formation depicted in Figure 2 shows the linear relationship between $\mathrm{HbA}_{1 \mathrm{c}}$ formation rate and time, with the slope proportional to the MPG [10]. The higher the blood glucose is, the faster $\mathrm{HbA}_{1 \mathrm{c}}$ will be formed, resulting in higher $\mathrm{HbA}_{1 \mathrm{c}}$ levels. It also demonstrates the distribution of $\mathrm{HbA}_{1 \mathrm{c}}$ amount in erythrocytes with different ages. For instance, it is elicited from the curve MPG $=137$, that the $\mathrm{HbA}_{1 \mathrm{c}}$ rate in newly born RBCs is $0 \%$, and in RBCs with 60 and 120 days old, 6 and $12 \%$, respectively.

It can be corroborated that the mean $\mathrm{HbA}_{1 \mathrm{c}}$ in a collection of erythrocytes with different ages and $\mathrm{HbA}_{1 \mathrm{c}}$ rates is the median point or arithmetic mean of the upper and lower limits of the curve. Erythrocyte life span in normal conditions is about 120 days and the level of $\mathrm{HbA}_{1 \mathrm{c}}$ at any point in time is contributed to by all circulating erythrocytes, from the oldest (120 days old) to the youngest. Since the rate of $\mathrm{RBC}$ formation is equal to its degradation, the percentage of $\mathrm{RBC}$ count in a single day is $1 / 120$ of total RBC mass. Hence, 1/120 of RBC collection are one day old, 1/120 are two days old, and likewise $1 / 120$ are 120 days old. The mean value of $\mathrm{HbA}_{1 \mathrm{c}}$ in a collection of RBCs with different ages can be calculated by averaging of $\mathrm{HbA}_{1 \mathrm{c}}$ rate in each $\mathrm{RBC}$ as follows:

$$
\text { Mean } \mathrm{HbA}_{1 \mathrm{c}}=\frac{\sum_{1}^{120} \varepsilon_{n} \times(1 / 120) \mathrm{RBC}_{\text {mass }}}{\mathrm{RBC}_{\text {mass }}} \text {, }
$$

where $\varepsilon_{n}$ is $\mathrm{HbA}_{1 \mathrm{c}}$ rate in $\mathrm{RBC}$ with $\mathrm{n}$ days old and $\mathrm{RBC}$ mass is total number of RBCs in the body. Since glycation of $\mathrm{Hb}$ according to Figure 2 follows a linear pattern, it is expected that

$$
\varepsilon_{2}=2 \varepsilon_{1}, \quad \varepsilon_{3}=3 \varepsilon_{1}, \ldots, \quad \varepsilon_{120}=120 \varepsilon_{1} .
$$

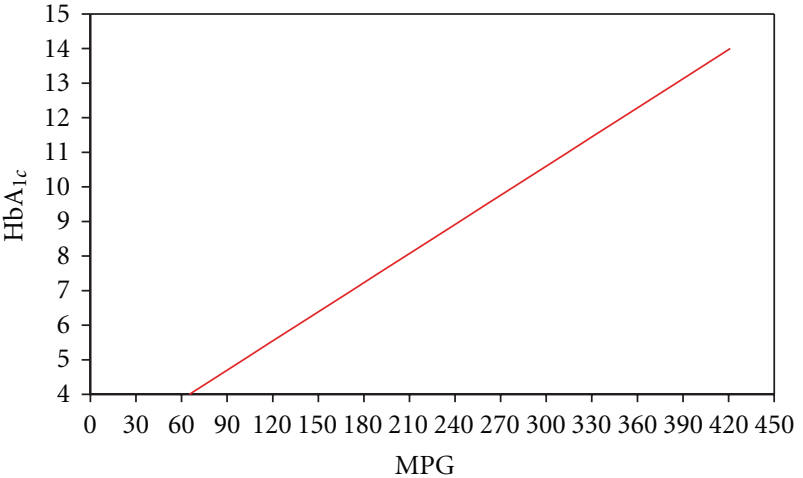

FIGURE 1: Linear regression analysis of MPG versus $\mathrm{Hb}_{1 \mathrm{c}}$ : the Pearson correlation coefficient $(r)$ is 0.82 ; MPG $(\mathrm{mg} / \mathrm{dl})=35.6 \times$

\begin{tabular}{|c|c|c|c|c|}
\hline \multirow{2}{*}{$\begin{array}{l}\mathrm{HbA}_{1 \mathrm{c}} \\
(\%)\end{array}$} & \multicolumn{2}{|c|}{ DCCT-estimated MPG } & \multicolumn{2}{|c|}{ ADAG-stimated MPG } \\
\hline & $\mathrm{mmol} / \mathrm{l}$ & $\mathrm{mg} / \mathrm{dl}$ & $\mathrm{mmol} / \mathrm{l}$ & $\mathrm{mg} / \mathrm{dl}$ \\
\hline 5 & 5.6 & 101 & 5.4 & 97 \\
\hline 6 & 7.6 & 137 & 7.0 & 126 \\
\hline 7 & 9.6 & 172 & 8.6 & 154 \\
\hline 8 & 11.5 & 208 & 10.2 & 183 \\
\hline 9 & 13.5 & 244 & 11.8 & 212 \\
\hline 10 & 15.5 & 279 & 13.4 & 240 \\
\hline 11 & 17.5 & 315 & 14.9 & 269 \\
\hline 12 & 19.5 & 350 & 16.5 & 298 \\
\hline
\end{tabular}
$\mathrm{HbA}_{\mathrm{lc}}-77.3$.

TABLE 1: Regression-estimated MPG at different $\mathrm{HbA}_{1 \mathrm{c}}$ levels based on DCCT and Nathan's data.

Hence,

$$
\begin{aligned}
\mathrm{HbA}_{1 c} & =\frac{(1 / 120) \mathrm{RBC}_{\text {mass }} \times\left(\varepsilon_{1}+\varepsilon_{120}\right) \times(120 / 2)}{\mathrm{RBC}_{\text {mass }}} \\
& =\frac{\left(\varepsilon_{1}+\varepsilon_{120}\right)}{2} .
\end{aligned}
$$

Accordingly, the mean value of $\mathrm{HbA}_{1 \mathrm{c}}$ in a collection of RBCs would be the arithmetic mean of upper and lower limits of the curve.

The mathematical relationship between data leading to the curves depicted in Figure 2 can be correlated by the following formula:

$$
\mathrm{HbA}_{1 \mathrm{c}}=\frac{\mathrm{MPG} / 35.6+2.17}{2} m,
$$

where MPG contributes the mean plasma glucose in which $\mathrm{Hb}$ glycation is progressing and $\mathrm{m}$ is the variation of time in month.

We will now map this model into mathematical expressions and start with an example.

Example 1. Assume that you have visited a diabetic patient with $\mathrm{HbA}_{\mathrm{lc}}=9 \%$ and $\mathrm{MPG}=244 \mathrm{mg} / \mathrm{dl}$ and after adjusting the medications, patient's MPG has fallen to the curve MPG = 137 as visualized by graphic presentation 


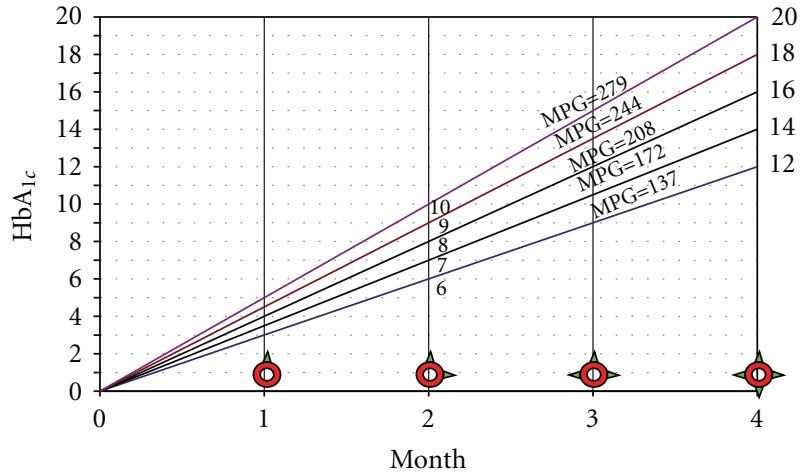

FIGURE 2: Rate of formation of $\mathrm{HbA}_{1 \mathrm{c}}$ simulated from results of prolonged incubation of $\mathrm{HbA}_{0}$ with glucose in different concentration.

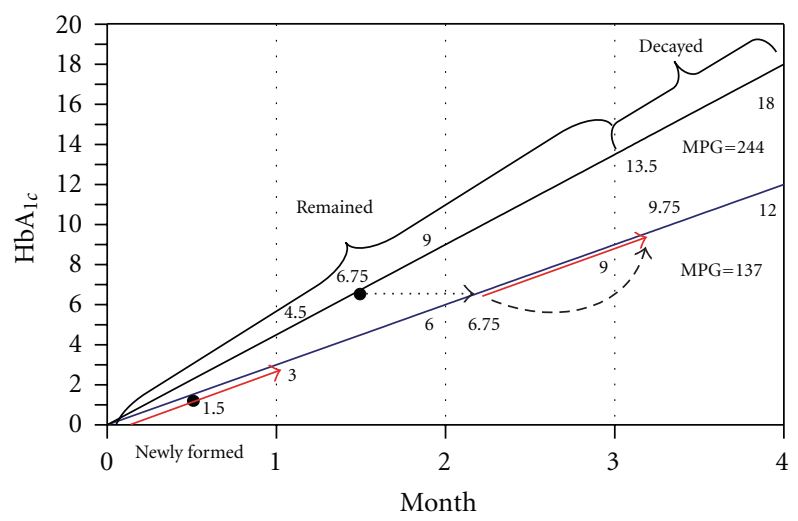

FIGURE 3: Plotted graph demonstrating process of events happening in the hypothetical Example 1.

in Figure 3. After one month you are interested in calculating the $\mathrm{HbA}_{1 \mathrm{c}}$ which is the mixture of previously and newly glycated $\mathrm{Hbs}$ and is estimated to be in range of $6 \%$ to $9 \%$.

As described in Figure 3, after passing one month of changes in MPG, the erythrocytes with 3 to 4 months old will reach the end of their lives and destroy themselves. The remaining RBCs have $\mathrm{HbA}_{1 \mathrm{c}}$ ranging from 0 to $13.5 \%$. This upper extreme can be calculated as

$$
\begin{aligned}
\Phi_{\text {Upper }} & =\frac{\mathrm{MPG}_{1} / 35.6+2.17}{2}(4-m)=\frac{\mathrm{Hb}_{1}}{2}(4-m) \\
& =13.5 \% .
\end{aligned}
$$

As described before (by (5)) the mean value of $\mathrm{HbA}_{1 \mathrm{c}}$ in this group of RBCs is arithmetic mean of upper and lower extremes of the curve, that is

$$
\begin{aligned}
\Phi_{\text {mean }} & =\frac{\Phi_{\text {Upper }}}{2}=\frac{\mathrm{MPG}_{1} / 35.6+2.17}{4}(4-m) \\
& =\frac{\mathrm{Hb}_{1}}{4}(4-m)=6.75 \% .
\end{aligned}
$$

Over the past one month, these previously glycated RBCs undergo new glycation on the curve MPG $=137$ to convey the prior mean $\mathrm{HbA}_{1 \mathrm{c}}$ to a newly higher point. This displacement of mean $\mathrm{HbA}_{1 \mathrm{c}}$ point on the second curve over $m$ months can be written as

$$
\Delta_{\Phi_{\text {mean }}}=\frac{\mathrm{MPG}_{x} / 35.6+2.17}{2} m=\frac{\mathrm{Hb}_{x}}{2} m=3 \% .
$$

The sum of contributions (8) and (9) represents the cumulative mean $\mathrm{HbA}_{1 \mathrm{c}}$ in this group of RBCs with former and later glycation on two different curves.

$$
\begin{aligned}
\Phi_{1} & =\frac{\mathrm{MPG}_{1} / 35.6+2.17}{4}(4-m)+\frac{\mathrm{MPG}_{x} / 35.6+2.17}{2} m \\
& =\frac{\mathrm{Hb}_{1}}{4}(4-m)+\frac{\mathrm{Hb}_{x}}{2} m=9.75 \% .
\end{aligned}
$$

Furthermore, during the past one month, second group of RBCs have been newly formed and undergone glycation on the new curve $(\mathrm{MPG}=137)$ with mean $\mathrm{HbA}_{1 \mathrm{c}}$ of

$$
\Phi_{2}=\frac{\mathrm{MPG}_{x} / 35.6+2.17}{4} m=\frac{\mathrm{Hb}_{x}}{4} m=1.5 \% \text {. }
$$

Following all above steps, we can find the final desired $\mathrm{HbA}_{1 \mathrm{c}}$ by averaging equations $\Phi_{1}$ and $\Phi_{2}$ considering their coefficients according to available RBCs in each group $(3: 1$, three months versus one month).

$$
\begin{aligned}
& \mathrm{Hb}_{\text {mix }}=\frac{\Phi_{2} \times m+\Phi_{1} \times(4-m)}{4}, \\
& \mathrm{Hb}_{\text {mix }}=\frac{\left(\left(\mathrm{MPG}_{x} / 35.6+2.17\right) / 4\right) m^{2}}{4} \\
& +\frac{\left(\frac{\mathrm{MPG}_{1}+2.17}{45.6}(4-m)+\frac{\frac{\mathrm{MPG}_{x}}{35.6}+2.17}{2} m\right)}{4} \\
& \times \frac{(4-m)}{4}, \\
& \mathrm{Hb}_{\text {mix }}=\frac{\left(\mathrm{Hb}_{x} / 4\right) m^{2}+\left(\left(\mathrm{Hb}_{1} / 4\right)(4-m)+\left(\mathrm{Hb}_{x} / 2\right) m\right)}{4} \\
& \times \frac{(4-m)}{4} .
\end{aligned}
$$

And rearranging gives

$\mathrm{Hb}_{\text {mix }}=\frac{\mathrm{MPG}_{x}\left(8 m-m^{2}\right)+\mathrm{MPG}_{1}\left(m^{2}-8 m+16\right)+1236}{570}$.

or

$$
\mathrm{Hb}_{\text {mix }}=\frac{\mathrm{Hb}_{x}\left(8 m-m^{2}\right)+\mathrm{Hb}_{1}\left(m^{2}-8 m+16\right)}{16}=7.6875 \% \text {. }
$$

Therefore, the estimated $\mathrm{HbA}_{1 \mathrm{c}}$ after one month would be $7.6875 \%$. Although this is the answer to our initial riddle, this value $\left(\mathrm{Hb}_{\text {mix }}\right)$ is a simply measurable variable by laboratory assays. In fact, our unknown desirable variable in this setting would be $\mathrm{MPG}_{x}$ and $\mathrm{Hb}_{x}$ representative of the second curve in which glycation occurs over recent months. And this is 


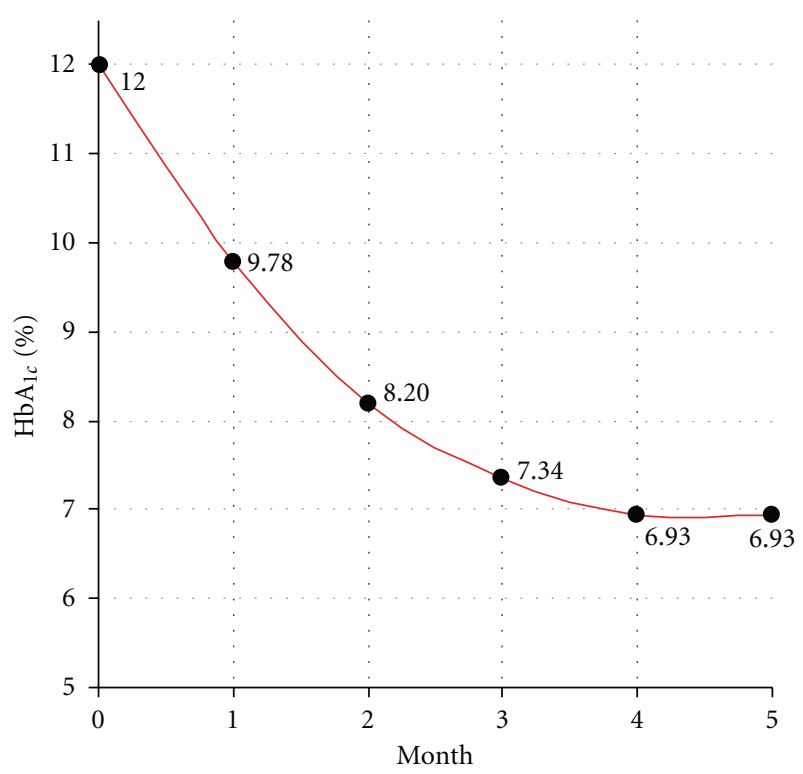

FIgURE 4: Changes in $\mathrm{HbA}_{\mathrm{lc}}$ versus time for the patient presented in Example 2.

the finding that was one of the most important limitations of $\mathrm{HbA}_{1 \mathrm{c}}$, some minutes ago.

Access to the equations governing $\mathrm{HbA}_{1 \mathrm{c}}$ by this comprehensive analysis could have potentially valuable implications on diabetes control. No matter how frequently done, measurement of $\mathrm{HbA}_{1 \mathrm{c}}$ can lead to the desirable mean plasma glucose over previous $m$ months and makes all doubts about time wasting over patient's observations, even. Finally, for practical aspects of this model in clinical setting,

$$
\mathrm{MPG}_{x}=\frac{570 \times \mathrm{Hb}_{\text {mix }}-\mathrm{MPG}_{1} \times\left(m^{2}-8 m+16\right)-1236}{\left(8 m-m^{2}\right)} .
$$

or

$$
\mathrm{Hb}_{x}=\frac{16 \times \mathrm{Hb}_{\operatorname{mix}}-\mathrm{Hb}_{1} \times\left(m^{2}-8 m+16\right)}{\left(8 m-m^{2}\right)},
$$

where

(i) $\mathrm{Hb}_{1}$ : initially measured $\mathrm{HbA}_{1 \mathrm{c}}$,

(ii) $\mathrm{Hb}_{\text {mix }}$ : measured $\mathrm{HbA}_{\mathrm{lc}}$ after $m$ months,

(iii) $\mathrm{Hb}_{x}: \mathrm{HbA}_{1 \mathrm{c}}$ corresponding to the curve on which the patient has moved during previous $m$ months,

(iv) $m$ : time interval between measured $\mathrm{Hb}_{1}$ and $\mathrm{Hb}_{\text {mix }}$ in month.

It is of note that, the final equation (16) is independent of presumed equations correlating $\mathrm{HbA}_{1 c}$ with MPG such as DCCT data ((1) and (2)) or other data such as Nathan's et al. [5]. The calculated $\mathrm{Hb}_{x}$ has a capability to be converted to the corresponding MPG using any of mentioned $\mathrm{HbA}_{1 \mathrm{c}^{-}}$ MPG relationships (Table 1).
TABle 2: Percentage of changes in $\mathrm{HbA}_{1 \mathrm{c}}$ during time intervals.

\begin{tabular}{lcccc}
\hline Month & First & Second & Third & Forth \\
\hline During & $44 \%$ & $31 \%$ & $17 \%$ & $8 \%$ \\
Total changes at the end of & $44 \%$ & $75 \%$ & $92 \%$ & $100 \%$ \\
\hline
\end{tabular}

Example 2. Assume a diabetic patient with $\mathrm{Hb}_{1}=12 \%$ and $\mathrm{MPG}_{1}=350$ to whom changing in therapeutic regimens is applied. After two weeks, the rechecked $\mathrm{HbA}_{1 \mathrm{c}}$ is $\mathrm{Hb}_{\text {mix }}=$ $11 \%$. According to (16), the mean plasma glucose in recent two weeks can be calculated as

$$
\mathrm{Hb}_{x}=\frac{16 \times 11-12 \times(0.25-4+16)}{(4-0.25)}=6.93 \%
$$

$\mathrm{Hb}_{x}=6.93 \%$ represents that the patient is shifted to and moving on the curve MPG $=170$ (see (1)) showing a significant improvement in patient's diabetic control. Otherwise, the measured $\mathrm{Hb}_{\text {mix }}=11 \%$ corresponds to the $\mathrm{MPG}=315$ with a remarkable error and deviation from reality due to a mixture of former and later glycated Hemoglobins.

It is of note that, variation in glycation rates between individuals and also difference in RBC life span especially in hemoglobinopathies are not factored in this model to attenuate intricacy of equations.

Another application of this derived mathematical model is describing the changes in $\mathrm{HbA}_{1 \mathrm{c}}$ with time. For the patient presented in Example 2, (14) takes the form of

$$
\mathrm{Hb}_{\text {mix }}=\frac{6.93 \times\left(8 m-m^{2}\right)+12 \times\left(m^{2}-8 m+16\right)}{16} .
$$

and can be plotted as in Figure 4 .

Percentage of changes in $\mathrm{HbA}_{1 \mathrm{c}}$ during the time intervals can be expressed as

$$
\Delta_{\mathrm{HbA}_{\mathrm{lc}}}=\frac{\mathrm{Hb}_{1}-\mathrm{Hb}_{\text {mix }}(\text { time }- \text { related })}{\mathrm{Hb}_{1}-\mathrm{Hb}_{x}} \times 100 .
$$

and is presented in Table 2 .

The calculated changes of $\mathrm{HbA}_{1 \mathrm{c}}$ over time derived from devised mathematical model are in full quantitative agreement with previous clinical studies [11-13] showing that plasma glucose levels in the preceding 30 days contribute $\sim 50 \%$ to the final results, and PG levels from 90-120 days earlier contribute only $\sim 10 \%$.

As briefly described, without applying the presented equations, early measurement of $\mathrm{HbA}_{1 \mathrm{c}}$ will end to a crude and erroneous estimation of patient's MPG. How frequently should it be checked is a great controversy among authorities, but the general trend and recommendation vary from 2 to 3 months.

Additional application of our mathematical model is calculation of emerged error at any desired time intervals, defined as deviation of the crude estimation of MPG derived 
TABLE 3: $\mathrm{MPG}_{1}$ versus $\mathrm{Hb}_{\text {mix }}$ showing estimated error of measured $\mathrm{HbA}_{1 \mathrm{c}}$ for detection of patient's MPG in 2-month intervals. Out of range data are ignored.

\begin{tabular}{lcccccccccc}
\hline Error2 & 101 & 137 & 172 & 208 & 244 & 279 & 315 & 350 & 385 & 420 \\
\hline 5 & 0 & -12.8 & -29.5 & -52.9 & & & & & \\
6 & 8.32 & 0 & -8.83 & -20.2 & -34.3 & -51.6 & & -50.8 & \\
7 & 12.37 & 6.723 & 0 & -6.86 & -15.4 & -25.1 & -36.9 & -28.5 & -38.4 & -49.9 \\
8 & 14.84 & 10.48 & 5.785 & 0 & -5.61 & -12.2 & -19.9 & -2.9 & -30.8 \\
9 & 16.51 & 12.96 & 9.203 & 4.987 & 0 & -4.59 & -10.2 & -16.3 & -23.1 & -13.8 \\
10 & 17.71 & 14.72 & 11.59 & 8.129 & 4.385 & 0 & -3.97 & -8.65 & -19.4 \\
11 & 18.61 & 16.03 & 13.35 & 10.42 & 7.281 & 4.01 & 0 & -3.39 & -7.47 & -11.9 \\
12 & 19.32 & 17.04 & 14.71 & 12.16 & 9.465 & 6.676 & 3.622 & 0 & -2.93 & -6.55 \\
13 & 19.88 & 17.85 & 15.78 & 13.54 & 11.17 & 8.742 & 6.102 & 3.383 & 0 & -2.55 \\
14 & 20.35 & 18.52 & 16.65 & 14.65 & 12.54 & 10.39 & 8.067 & 5.689 & 3.184 & 0 \\
\hline
\end{tabular}

TABLE 4: $\mathrm{MPG}_{1}$ versus $\mathrm{Hb}_{\text {mix }}$ showing estimated error of measured $\mathrm{HbA}_{1 \mathrm{c}}$ for detection of patient's MPG in 3-month intervals.

\begin{tabular}{lcccccccccc}
\hline Error3 & 101 & 137 & 172 & 208 & 244 & 279 & 315 & 350 & 385 & 420 \\
\hline 5 & 0 & -2.27 & -4.76 & -7.44 & -10.3 & -13.2 & -16.3 & -19.5 & -22.9 & -26.5 \\
6 & 1.846 & 0 & -1.62 & -3.47 & -5.39 & -7.33 & -9.4 & -11.5 & -13.7 & -15.9 \\
7 & 2.806 & 1.469 & 0 & -1.28 & -2.73 & -4.19 & -5.73 & -7.27 & -8.85 & -10.5 \\
8 & 3.427 & 2.336 & 1.25 & 0 & -1.06 & -2.22 & -3.45 & -4.66 & -5.91 & -7.19 \\
9 & 3.861 & 2.939 & 2.026 & 1.069 & 0 & -0.88 & -1.89 & -2.9 & -3.92 & -4.97 \\
10 & 4.182 & 3.384 & 2.596 & 1.772 & 0.933 & 0 & -0.76 & -1.62 & -2.49 & -3.38 \\
11 & 4.428 & 3.725 & 3.032 & 2.308 & 1.574 & 0.849 & 0 & -0.65 & -1.41 & -2.18 \\
12 & 4.624 & 3.996 & 3.377 & 2.732 & 2.078 & 1.434 & 0.763 & 0 & -0.57 & -1.25 \\
13 & 4.783 & 4.215 & 3.656 & 3.074 & 2.485 & 1.906 & 1.303 & 0.71 & 0 & -0.5 \\
14 & 4.914 & 4.396 & 3.886 & 3.357 & 2.821 & 2.295 & 1.747 & 1.209 & 0.665 & 0 \\
\hline
\end{tabular}

via $\mathrm{Hb}_{\text {mix }}$, from real MPG calculated by devised equations

$$
\text { error }=\frac{M P G_{\text {real }}-M P_{\text {crude }}}{M P G_{\text {real }}} \times 100 \text {. }
$$

or

$$
\text { error }=1-\frac{\left(35.6 \times \mathrm{Hb}_{\text {mix }}-77.3\right)}{\left(\frac{570 \times \mathrm{Hb}_{\text {mix }}-\mathrm{MPG}_{1} \times\left(m^{2}-8 m+16\right)-1236}{\left(8 m-m^{2}\right)}\right)} \times 100 \text {. }
$$

To make the presented 3-variable equation more applicable, it can be used at definite points of time with different values of $\mathrm{MPG}_{1}$ and laboratory measured $\mathrm{Hb}_{\mathrm{mix}}$. As an instance, error estimation of measured $\mathrm{HbA}_{\mathrm{lc}}$ for detection of patient's mean plasma glucose in 2 and 3 months intervals is expressed in Tables 3 and 4 according to different values of $M P G_{1}$ and $\mathrm{Hb}_{\text {mix }}$.

As presented in Tables 3 and 4, estimated error emerged in different values of $\mathrm{MPG}_{1}$ and $\mathrm{Hb}_{\text {mix }}$ ranges from $-50 \%$ to $+20 \%$ for 2 -month interval and $-26 \%$ to $+5 \%$ for 3 -month interval. Negative and positive errors contribute to overestimation and underestimation of patient's MPG, respectively. The higher the difference between $\mathrm{Hb}_{1}$ and $\mathrm{Hb}_{\text {mix }}$ is, the bigger the error emerged from crude estimation of patient's MPG via laboratory measured $\mathrm{Hb}_{\text {mix }}$.

\section{Discussion}

Hemoglobin is continuously glycated during the 120-day life span of erythrocyte such that the cumulative amount of $\mathrm{HbA}_{1 \mathrm{c}}$ in an erythrocyte is directly proportional to the timeaveraged concentration of glucose within the erythrocyte $[8,10,14,15]$. Glycated hemoglobins provide an index of the patient's average blood glucose concentration over a long time period. This index is not affected by short-term fluctuations in blood sugar (hour to hour) and hence gives a relatively precise reflection of the state of blood glucose control in diabetes.

To introduce novel applications and new concepts about $\mathrm{HbA}_{1 \mathrm{c}}$, an innovative mathematical simulation was analytically modeled to describe the $\mathrm{HbA}_{1 \mathrm{c}}$ behavior and process of events. The basic suppositions are cited from available equations expressed in Figures 1 and $2[9,10]$. The devised model is used to predict the mean plasma glucose at any desired point in time with great certainty. By using derived formulas, it does not take 120 days to detect a clinically meaningful and reliable value for $\mathrm{HbA}_{1 \mathrm{c}}$ and $\mathrm{MPG}$ over preceding months.

In addition to the presented application, I specifically was interested in assessing the pattern of $\mathrm{HbA}_{1 \mathrm{c}}$ changes over time and calculation of emerged error during crude estimation of MPG from $\mathrm{Hb}_{\text {mix }}$. As described in Table 2 
and Figure 4, change in $\mathrm{HbA}_{1 c}$ shows a prompt fall upon institution of rigorous diabetic control. This finding can be readily explained by decay of older erythrocytes with highest rates of glycated $\mathrm{Hb}$, as demonstrated in Figure 3. This model refutes the explanation that recent PG levels (i.e., 3-4 weeks earlier) contribute considerably more to the level of $\mathrm{HbA}_{1 \mathrm{c}}$ than do long past PG levels (i.e., 3-4 months earlier) [11-13].

According to calculated error for 2- and 3-month interval and its explained logic, without employment of the devised model, $\mathrm{HbA}_{1 \mathrm{c}}$ should be used with caution as a surrogate measure of MPG because it may significantly under or overestimate patient's MPG.

The tests currently in use for diagnosis are the fasting plasma glucose test and the less common oral glucose tolerance test. However, these tests can be inaccurate if a person has eaten recently or is sick. Advantages of the $\mathrm{HbA}_{\mathrm{lc}}$ test are that it can be given at any time and, because it reflects blood glucose levels over a longer period, it is not unduly influenced by events on the day of the test. This devised model also makes $\mathrm{HbA}_{1 \mathrm{c}}$ more befitting and useful for being a main part of guidelines on using the $\mathrm{HbA}_{1 \mathrm{c}}$ test as a diagnostic tool for diabetes. However, a consensus statement is necessary because right now there is no agreement on what $\mathrm{HbA}_{1 \mathrm{c}}$ level would constitute a diagnosis of diabetes.

\section{Acknowledgment}

Dr. Mahdi Kahrom has devised this model and written the paper. No conflicts of interest. No funding sources.

\section{References}

[1] F. J. Service, "Correlation between glycemia and glycated hemoglobin," Comprehensive Therapy, vol. 16, no. 7, pp. 3340, 1990.

[2] O. B. Crofford, S. Genuth, and L. Baker, "Diabetes Control and Complications Trial (DCCT): results of feasibility study," Diabetes Care, vol. 10, no. 1, pp. 1-19, 1987.

[3] R. J. Koenig, C. M. Peterson, R. L. Jones, C. Saudek, M. Lehrman, and A. Cerami, "Correlation of glucose regulation and hemoglobin A1C in diabetes mellitus," The New England Journal of Medicine, vol. 295, pp. 417-420, 1976.

[4] P. A. Svendsen, T. Lauritzen, U. Soegaard, and J. Nerup, "Glycosylated haemoglobin and steady-state mean blood glucose concentration in type 1 (insulin-dependent) diabetes," Diabetologia, vol. 23, no. 5, pp. 403-405, 1982.

[5] D. M. Nathan, J. Kuenen, R. Borg, H. Zheng, D. Schoenfeld, and R. J. Heine, "The Alc-Derived Average Glucose (ADAG) Study Group. Translating the A1C assay into estimated average glucose values," Diabetes Care, vol. 31, no. 1, pp. 1473-1478, 2008.

[6] M. B. Davidson, D. L. Schriger, A. L. Peters, and B. Lorber, "Revisiting the oral glucose tolerance test criterion for the diagnosis of diabetes," Journal of General Internal Medicine, vol. 15, no. 8, pp. 551-555, 2000.

[7] American Diabetes Association: Clinical Practice Recommendations 2001, "Standards of medical care for patients with diabetes mellitus," Diabetes Care, vol. 24, pp. 533-550, 2002.

[8] H. F. Bunn, D. N. Haney, S. Kamin, K. Gabbay, and P. Gallop, "The biosynthesis of human hemoglobin Alc," Journal of Clinical Investigation, vol. 57, no. 6, pp. 1652-1659, 1976.
[9] C. L. Rohlfing, H.-M. Wiedmeyer, R. R. Little, J. D. England, A. Tennill, and D. E. Goldstein, "Defining the relationship between plasma glucose and $\mathrm{HbA}_{1 c}$ : analysis of glucose profiles and $\mathrm{HbA}_{1 \mathrm{c}}$ in the Diabetes Control and Complications Trial," Diabetes Care, vol. 25, no. 2, pp. 275-278, 2002.

[10] P. J. Higgins and H. F. Bunn, "Kinetic analysis of the nonenzymatic glycosylation of hemoglobin," Journal of Biological Chemistry, vol. 256, no. 10, pp. 5204-5208, 1981.

[11] Y. Tahara and K. Shima, "The response of GHb to stepwise plasma glucose change over time in diabetic patients," Diabetes Care, vol. 16, no. 9, pp. 1313-1314, 1993.

[12] Y. Tahara and K. Shima, "Kinetics of $\mathrm{HbA}_{1 c}$, glycated albumin, and fructosamine and analysis of their weight functions against preceding plasma glucose level," Diabetes Care, vol. 18, no. 4, pp. 440-447, 1995.

[13] D. E. Goldstein, R. R. Little, H. M. Wiedmeyer, J. D. England, and C. L. Rohlfing, "Glycohemoglobin testing in diabetes mellitus: assay methods and clinical interpretation," in Drugs in Development, J. R. Vasselli, C. A. Maggio, and A. Scriabine, Eds., pp. 253-267, Neva Press, Branford, Conn, USA, 1993.

[14] K. W. Beach, "A theoretical model to predict the behavior of glycosylated hemoglobin levels," Journal of Theoretical Biology, vol. 81, no. 3, pp. 547-561, 1979.

[15] R. Fluckiger and K. H. Winterhalter, "In vitro synthesis of hemoglobin AIc," FEBS Letters, vol. 71, no. 2, pp. 356-360, 1976. 


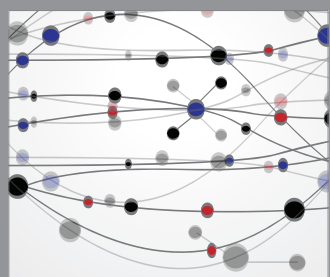

The Scientific World Journal
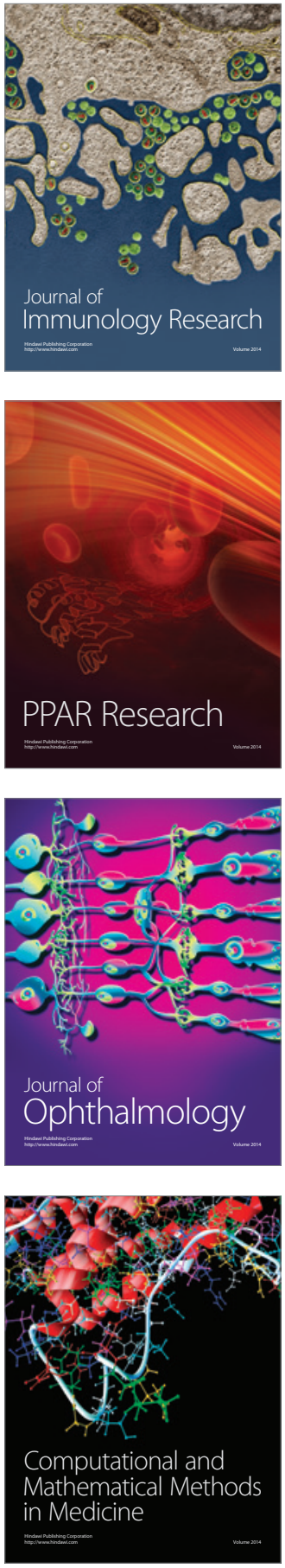

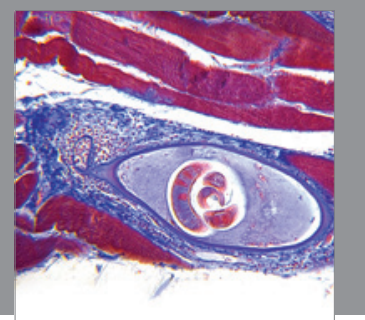

Gastroenterology

Research and Practice
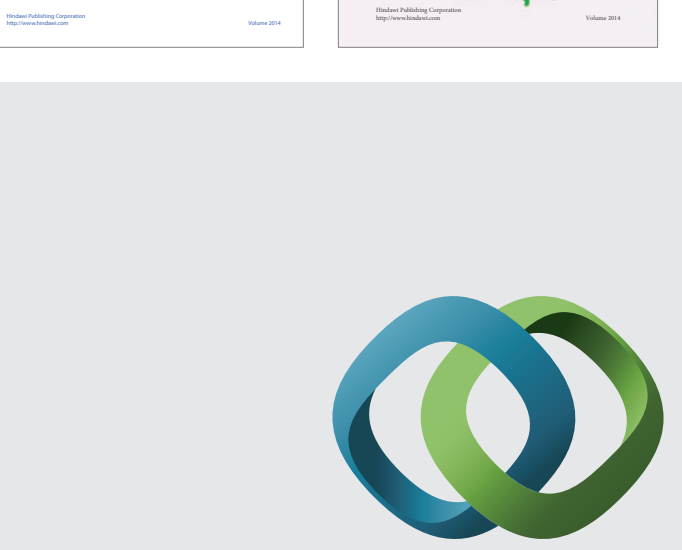

\section{Hindawi}

Submit your manuscripts at

http://www.hindawi.com
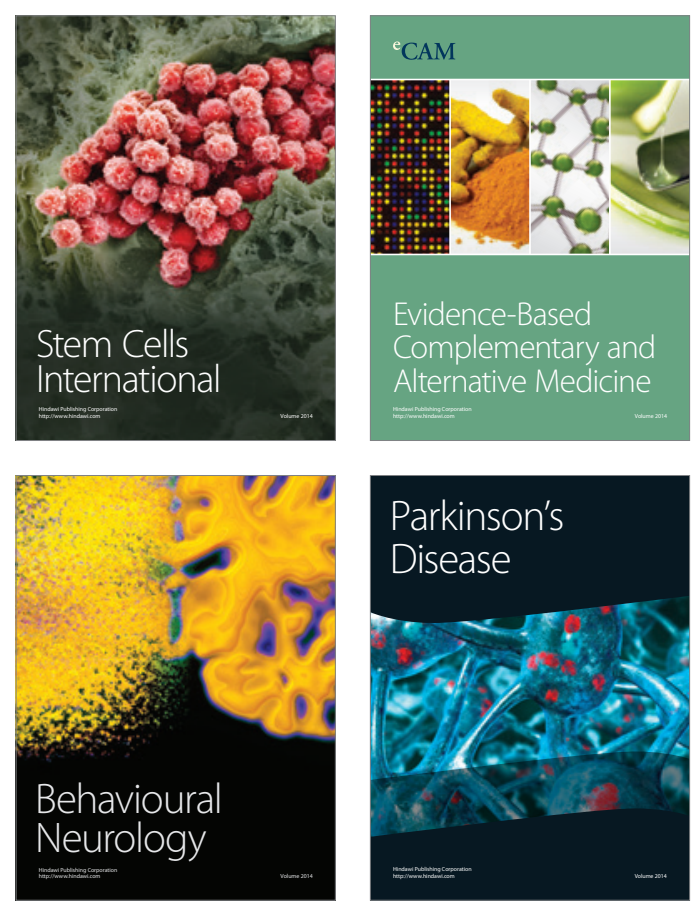

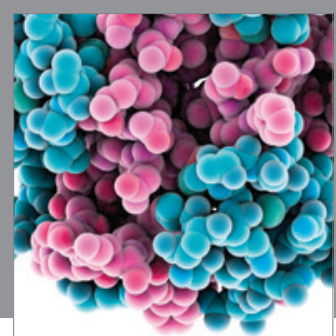

Journal of
Diabetes Research

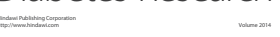

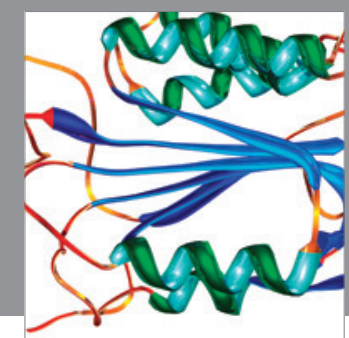

Disease Markers
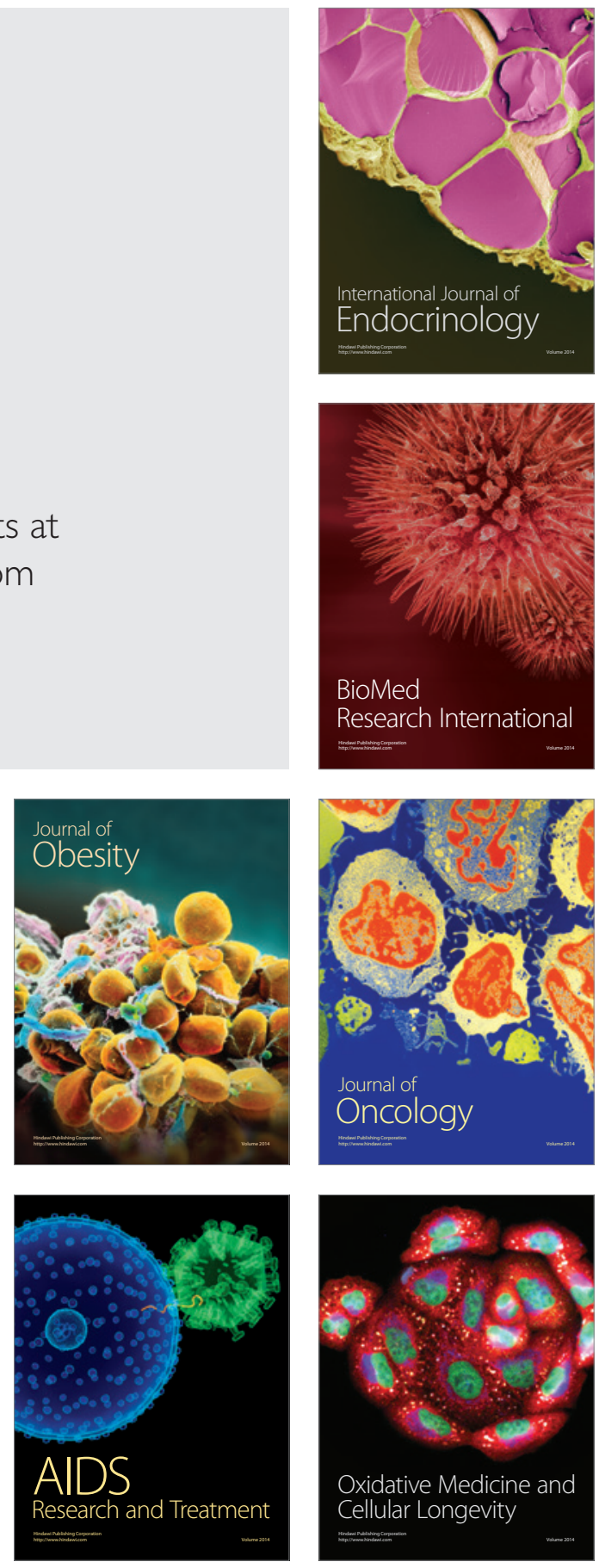